\title{
FEASIBILITY EVALUATION OF A BIODIESEL PLANT FED BY RECYCLED EDIBLE OILS COMPARING TWO ALTERNATIVE PRODUCTION TECHNOLOGIES
}

KORAKAKI M. GEORGAKELLOS D.*

\author{
University of Piraeus \\ Department of Business Administration \\ Karaoli \& Dimitriou 80 \\ 18534 Piraeus, Greece
}

Received: 07/10/13

Accepted: 05/02/14

*to whom all correspondence should be addressed

Available online: 06/02/2014

\begin{abstract}
The present work is about the techno-economic evaluation of a biodiesel industrial unit that exclusively use recycled edible oils as feedstock, for two alternative production technologies. Nowadays, many biodiesel production units use a mixture of virgin vegetable oils and waste cooking oils. The examined unit will use only waste cooking oil as raw material. Thus, two different methods for biodiesel production are assessed on a financial basis for different biodiesel prices. The investigated methods are the alkaline transesterification (a very common biodiesel production method) and the supercritical transesterification (a method with non sensitivity in moisture and free fatty acids and thus not requiring a pre-treatment stage). According to the financial evaluation, the acceptance of the project for each technology is strongly affected by biodiesel's price. The results showed that the alkaline transesterification based project is accepted for the whole examined prices' range while for supercritical transesterification, the project is accepted for biodiesel prices of about $0.75-0.85 € / L$.
\end{abstract}

Keywords: Biodiesel, Waste Cooking Oil, Transesterification, Feasibility Study

\section{Introduction}

Worldwide, people are increasingly interested in environmental issues and preservation of non renewable natural resources. Since many years, people are turning to products that are not polluting the environment and to those that are somehow protecting the environment (Georgakellos, 2002; San Miguel et al., 2010). Undoubtedly, biofuels have won people's interest due to their advantages against fossil fuels. This fact is constantly verified by investing huge amounts in research and development at the sector of biofuels and in general in "green" transportations (Kretzschmar et al., 2012). However, it is of vital importance the biodiesel production to be in a viable basis based on the protection of the environment, natural resources and economy. Towards this direction the present work aims to investigate the feasibility of a typical biodiesel production unit fed by recycled waste edible oils. The research for alternative sources of energy has already begun, proving the necessity of a sustainable future.

\section{The Greek market of biodiesel}

According to the European Union (EU) Directive 2003/30/EC, the promotion and the gradual use of biofuels as an alternative transport fuel in Greece becomes mandatory, for the partial substitution of 
diesel and gasoline fuels with fuels derived from agricultural sources (biodiesel, bioethanol). The goal was $2 \%$ of transport fuels by 2005 and $5.75 \%$ by 2010 to come from renewable energy sources (European Parliament, 2003). Furthermore, according to the Greek law, liquid and gaseous biofuels and other renewable fuels should replace refined crude oil products in their respective categories and uses, either alone or in mixture with refined crude oil products (Hellenic Republic, 2005).

It must be mentioned that in Greece until today biodiesel is considered as the only biofuel used in the transportation sector since bioethanol is not at all used. The main reason referring to bioethanol absence in the Greek fuels market is rather a technical kind of obstacle. Despite the fact that long - term bioethanol use in blends usually results in degradation of vehicle engine's materials due to its corrosive properties, there are further technical details that must be mentioned. Bioethanol added in gasoline results in the increase of vapour pressure especially in summertime. On the other hand, bioethanol used in cold climates or during wintertime causes cold - start problems in vehicles. Furthermore, the use of a gasoline substitute fuel as ethanol, even in small blends, would result in further gasoline surplus and consequently to a decrease of gasoline's market price, fact that is against to refineries policy (Papageorgiou, 2009).

The future demand for biodiesel is affected by many factors. One of them is the European Union policies, which have already set as a goal the $10 \%$ of transportation fuels in the EU countries by 2020 to derive from biofuels, goal for which Greece has already been committed. Additionally, the position of Greek government concerning the fuels used for transport will play an important role in future demand for biodiesel, with the release of diesel use to be one of the major factors that will outline future demand for biodiesel. The release of diesel use in cars in Athens and Thessaloniki, will gradually lead to increased demand in diesel. This should be seen as a good opportunity to allow the use of dieselbiodiesel mixtures with a higher percentage in biodiesel. Considering this evidence, the forecast of future demand for diesel and biodiesel for the period $2012-2020$ is given in Figure 1, calculated using the statistical package MINITAB. The requirements in biodiesel are resulted from the estimated consumption of diesel fuel for use in transport and the rate of biodiesel penetration with an annual increase around $7 \%$, according to the objectives set by Greece to achieve the target of $10 \%$ in transport biofuels by 2020 .

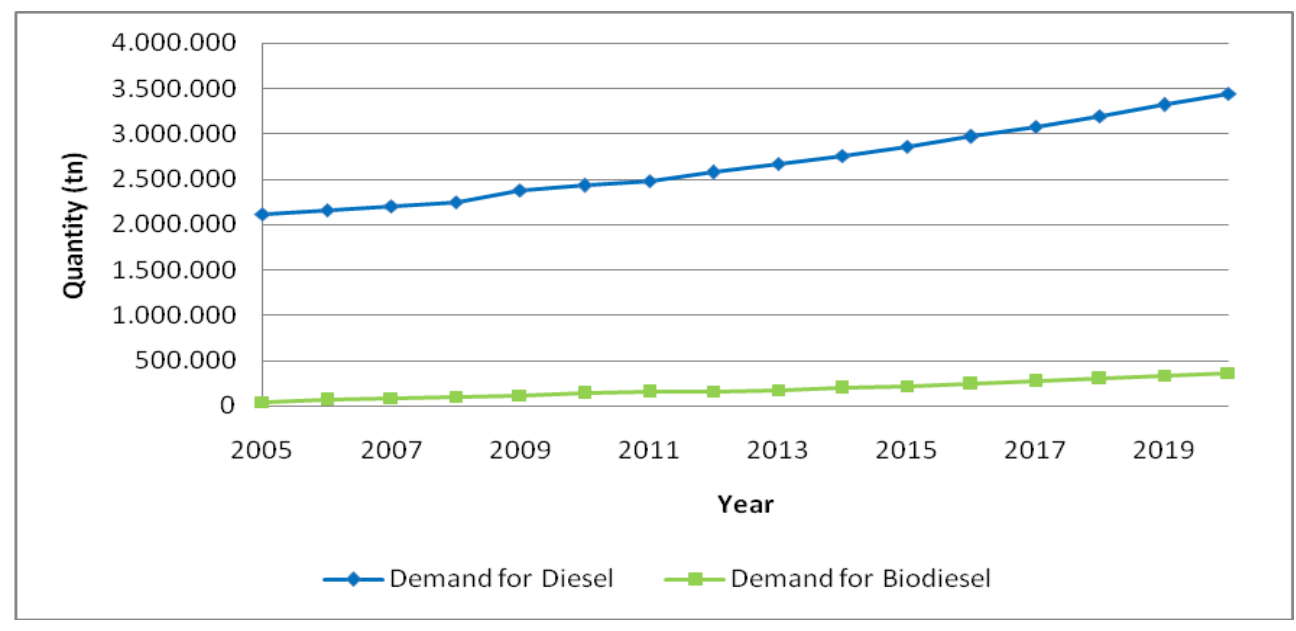

Figure 1. Domestic Demand Forecast for Diesel and Biodiesel

Biodiesel producers' customers are the Greek refineries. The latter ones form biodiesel prices after negotiation with each producer individually, taking into account the cost of raw materials and the respective production cost. Biodiesel that is currently available in the Greek market shows a range in price between $0.55-0.85 € / \mathrm{L}$. The final price depends on the price and availability of raw material. The biodiesel production involves several stakeholders from the agricultural sector, biodiesel producers and refineries. As a result, its production is considered as a complex process and many factors affect 
product's increased price (Papageorgiou, 2009). The estimated total revenues from sales of biodiesel depend on the quantity of biodiesel sold and the price of the selling product. The average annual increase in the amount of biodiesel that will enter in the Greek market will be around to 7\% (according to the objectives of marketing), while the price of biodiesel is adjusted annually based on the foreseen inflation for Greece.

On the other hand, glycerin is the main byproduct of biodiesel production, as this is a product of a commercial value, providing a secondary revenue stream for biodiesel producers or offsetting the cost of producing biodiesel. Until recently, refined glycerin was regarded as a commercial valuable byproduct, used in the production of pharmaceuticals and personal care products. Though, glycerin produced from biodiesel can not be absorbed by the traditional market and the created surplus causes a sharp decline in the price of glycerin. In several studies on this subject, significant amount of revenues have been attributed to the refined glycerin. However, since this is not the state of the market currently, no revenues from glycerin commercialization have been projected in the present case study (Apostolakou et al., 2009).

\section{Waste Cooking Oil}

As waste cooking oils are defined the used oils generated by the food industry, restaurants and households and are no longer to be consumed from humans (Groschen, 2002; Gui et al., 2008; Peiro et al., 2008). Waste cooking oils have not strictly defined properties. This is because waste cooking oils are usually derived from a mixture of oils and/ or animal fats with different physical and chemical characteristics. In respect to waste cooking oils' physical characteristics, the most noticeable refers to its form, as most oils are liquid in room temperatures (Papageorgiou, 2009). They are biodegradable and insoluble in water, but soluble in organic solvents. Beyond their physical characteristics, the degree of denaturation of oil is affected by external factors such as the composition of the food, the frying temperature, exposure to oxygen, heating time and equipment used for frying (Chherti et al., 2008; Papageorgiou, 2009).

Table 1. Comparison of Properties of Waste Cooking Oil, Biodiesel from Waste Cooking Oil and Commercial Diesel Fuel

\begin{tabular}{|c|c|c|c|c|}
\hline Fuel Property & $\begin{array}{c}\text { Waste } \\
\text { Cooking Oil }\end{array}$ & $\begin{array}{c}\text { Biodiesel from } \\
\text { Waste Cooking Oil }\end{array}$ & $\begin{array}{l}\text { Commercial } \\
\text { Diesel Fuel }\end{array}$ & EN 14214 \\
\hline $\begin{array}{c}\text { Kinematic Viscosity }\left(\mathrm{mm}^{2} \mathrm{~s}^{-1}\right. \\
\left.\text { at } 40^{\circ} \mathrm{C}\right)\end{array}$ & 36.4 & 5.3 & $1.9-4.1$ & $3.5-5.0$ \\
\hline Density $\left(\mathrm{kg} \mathrm{I}^{-1}\right.$, at $\left.15^{\circ} \mathrm{C}\right)$ & 0.924 & 0.897 & $0.075-0.840$ & $0.86-0.9$ \\
\hline Flash Point $\left({ }^{\circ} \mathrm{C}\right)$ & 212 & 196 & $67-85$ & 120 min. \\
\hline Pour Point $\left({ }^{\circ} \mathrm{C}\right)$ & 11 & -11 & $(-19)-(-13)$ & - \\
\hline Cetane Number & 49 & 54 & $40-46$ & $51.0 \mathrm{~min}$. \\
\hline Ash Content (\%) & 0.006 & 0.004 & $0.008-0.010$ & $0.02 \max$ \\
\hline Sulfur Content (\%) & 0.09 & 0.06 & $0.35-0.55$ & $0.001 \max$ \\
\hline Carbon Residue (\%) & 0.46 & 0.33 & $0.35-0.40$ & $0.30 \max$ \\
\hline Water Content (\%) & 0.42 & 0.04 & $0.02-0.05$ & $0.05 \max$ \\
\hline Free Fatty Acid (mg KOH/g oil) & 1.32 & 0.10 & - & $0.50 \max$ \\
\hline Saponification Value & 188.2 & - & - & - \\
\hline lodine Value & 141.5 & - & - & 120 max. \\
\hline
\end{tabular}

The quality of waste cooking oils is expected to vary as it depends on the type of vegetable oil used, the different culinary practices and the systems for collection and storage of waste oils (Oliveros et al., 2007). Additionally, different oils are used under the same conditions - high and long exposure time frying temperatures - resulting to different characteristics (Papageorgiou, 2009). During frying, vegetable oils are used at very high temperatures. This process causes several chemical reactions such as hydrolysis, polymerization and oxidation. Therefore, physical and chemical properties of the oil change during frying. The free fatty acids percentage has be found to increase because of oxidation and 
hydrolysis of triglycerides in the presence of moisture in food. Increase in viscosity has been also referred because of polymerization, which leads to the formation of high molecular weight compounds. Other observations are related to the increase in acid number, density and saponification index in fried oil and a decrease in iodine value (Canakci, 2007). Table 1 presents the properties of waste cooking oil, biodiesel from waste cooking oil and commercial diesel fuel (Demirbas, 2009).

Biodiesel production from waste cooking oil is considered as a commercial/ industrial method for reusing waste cooking oil (Tsai et al., 2005; Wang et al., 2007). Almost all the triglycerides, even from poor quality, can be converted into high quality biodiesel fuel, without significant pre-treatment (Deshpande et al., 2010). According to literature, the conversion yield of waste cooking oil into biodiesel has been reported to be around $80-90 \%$, depending on the quality of waste cooking oil, the process for refining, technology and practices used during transesterification (Papageorgiou, 2009). In the present case study, based on the most conservative estimate, the yield of conversion was assumed to be $80 \%$, thus ensuring the desired produced quantity of biodiesel even for the worst quality of raw material used.

\section{Biodiesel Production}

In our case the unit's annual capacity will be 15,000 tonnes of biodiesel per year. However, for the first year of operation, the production will be 5,000 tonnes of biodiesel. The product will conform to the specifications of EN 14214. The ccurrent available technologies to convert waste cooking oil to biodiesel are (a) the acid - catalyzed transesterification, (b) the alkaline transesterification, (c) the enzymatic catalyzed conversion, (d) the ultrasound method and (e) the supercritical transesterification (Demirbas, 2009; Fan et al., 2010; Gui et al., 2008; van Kasteren, 2007; Papageorgiou, 2009). The methods examined here are the alkaline transesterification and the supercritical transesterification. Industrially, alkaline transesterification is widely used as a transesterification process. Initially, vegetable oils were the raw materials used. Subsequently, waste cooking oils were added to form a mixture for process's input but the production process needed to be modified (i.e. a pre-treatment stage was added for waste cooking oils). Supercritical transesterification is cost competitive compared to conventional catalytic process, especially when poor quality raw materials are used.

Supercritical transesterification needs a larger capital cost, compared to alkaline transesterification, due to the required heating and pumping systems. However, supercritical method is non-sensitive to moisture and free fatty acids and does not require catalyst, thus resulting in a reduced operational cost as waste cooking oils do not require a pre - treatment stage. The feedstock quality is far less influential under supercritical conditions resulting to a great advantage for waste cooking oils to be used as raw material (Ngamprasertsith et al., 2011). Free fatty acids and moisture are undesirable when alkaline transesterification is to be used. This is because their presence can cause the formation of soaps and de - activation of catalyst. However, the presence of moisture affects positively the supercritical transesterification. The fact that stages as pre - treatment, removal of soaps and catalyst are not needed, results to the decline of capital cost, but the expected high operational cost, due to high pressure and temperature, can be a disadvantage for the supercritical method. Thus, it is crucial to assess the competitiveness of the supercritical method in order to consider it in a biodiesel production unit (Castellanelli et al., 2007; Demirbas, 2009; Dmytryshyn et al., 2004; Gui et al, 2008; Helwani et al., 2009; Ngamprasertsith et al., 2011).

Biodiesel is produced via transesterification which is a catalyzed chemical reaction of vegetable oils or animal fats with a short aliphatic alcohol (usually methanol or ethanol). The chemical reaction for biodiesel production requires the presence of a catalyst, usually a strong base such as sodium hydroxide $(\mathrm{NaOH})$ or potassium hydroxide $(\mathrm{KOH})$, to produce methyl esters, known as biodiesel. In the case of alkaline transesterification, a pre - treatment stage for raw material is necessary, as its quality varies on the content of free fatty acids and moisture. After waste cooking oils are controlled for their quality, they are entered into a sedimentation tank in order any impurities to be removed from waste cooking oils. Then oil is heated to remove moisture and then it is pumped under vacuum to further remove 
moisture. Removal of water is an important factor as its presence can cause hydrolysis in triglycerides and this can block the desired transesterification reaction. The conversion of waste cooking oil after this refining process is expected to be around $88 \%$ (Papageorgiou, 2009). After that, refined waste cooking oils are heated and then they are entered into the transesterification reactor.

For transesterification a base is needed in order to act as a catalyst. In this case sodium hydroxide will be used. The required quantity of base is mixed with excess of alcohol until complete dissolution. In literature, the required alcohol is in the ratio 3:1, alcohol/ oil, but alcohol is added in excess, to a ratio $6: 1$, in order to drive the reaction towards completion, as the reaction is bidirectional and the surplus of alcohol will lead the reaction to the right side, ensuring complete conversion. The aqueous solution of alcohol/ catalyst is first heated and then is introduced to the reactor, where heated oil has already been entered. The reaction requires a temperature of about $65{ }^{\circ} \mathrm{C}$ (a greater temperature than the boiling point of the alcohol) and duration of approximately 4 hours. During transesterification, the alcohol reacts with free fatty acids to produce a mono-alky-ester (biodiesel) and crude glycerol. The products are led to separation. The phase of glycerin is denser than the biodiesel phase and the two phases can be separated by gravity, as glycerin can be easily removed from the bottom of the separator vessel. Glycerin is a byproduct with commercial value that can be sold for further refining and utilization.

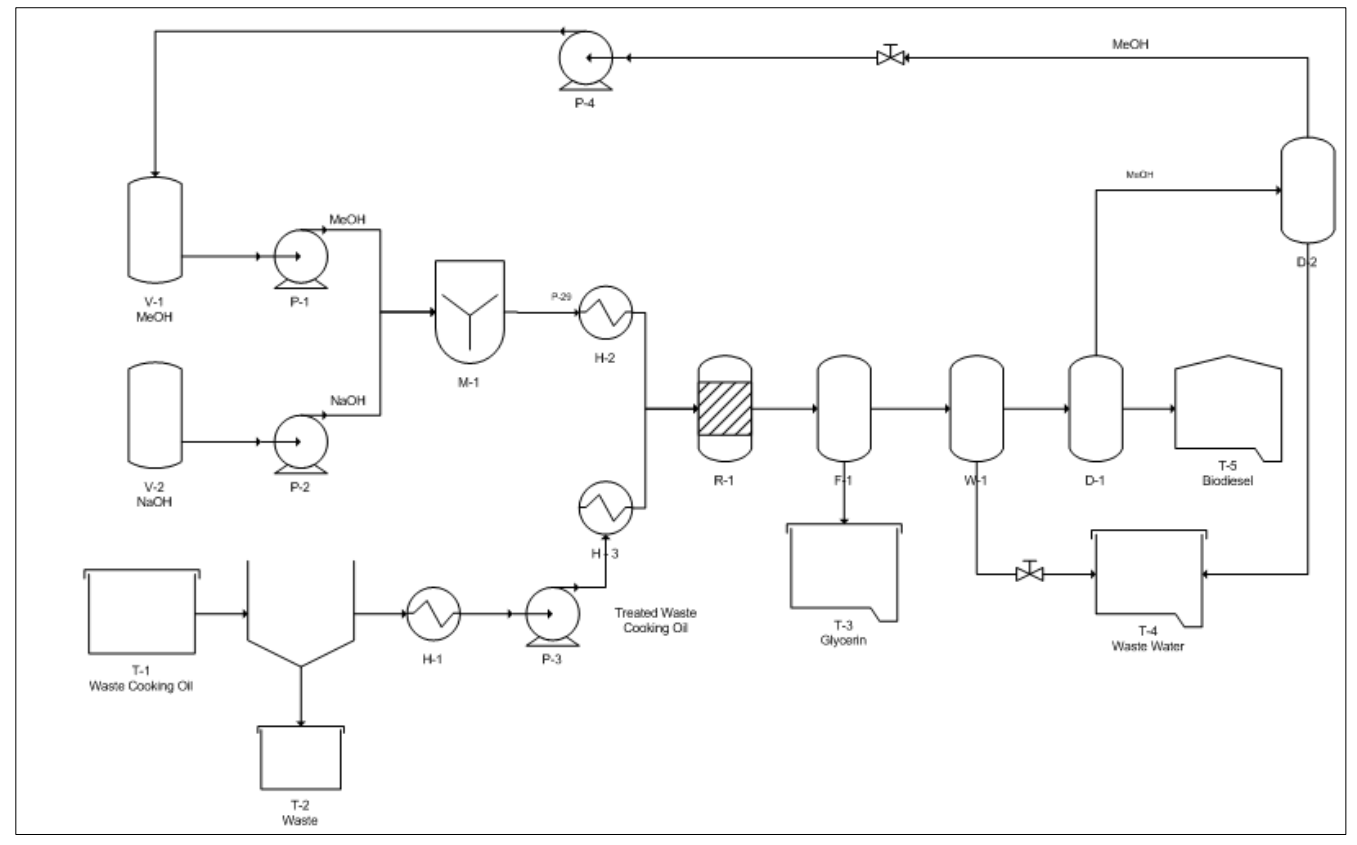

Figure 2. Flow Process Diagram for Alkaline Transesterification (Adapted from Fukuda et al., 2001; Stephenson et al., 2008; Zhang et al., 2003)

The following stages of the process include washing of methyl esters, by adding heated water and sulfuric acid solution (10\%). The required quantity of water is about $12 \%$ of the respective quantity of methyl esters and the washing is necessary so as catalyst will be neutralized and soaps will be converted to free fatty acids. The lower phase of the mixture is waste water that should be directed to the processing plant to be disposed safely in the environment. The next stage refers to methanol recovery. The upper phase of the previous stage is a mixture of biodiesel and alcohol that will be separated by distillation. Biodiesel is then dried and stored under carefully controlled conditions. The surplus of the alcohol is recovered by distillation. The recovery in this stage is referred to be about $95 \%$ and the recovered quantity is used in the production process.

In supercritical transesterification there is no need for a pre-treatment stage. This is because the process can conducted in the presence of moisture or/ and high free fatty acid content, allowing a wide range of raw materials to be used. In this process, methanol is used in a ratio of 42:1. Oil and alcohol are 
introduced to the supercritical reactor, where by using supercritical methanol at high temperatures and pressures, oil and methanol constitute a single phase and reaction occurs spontaneously and rapidly. The streams of the product are used to pre - heat the feed streams (alcohol and oil). Products are then moved to the separation vessel, where the lower phase of glycerin is removed for further processing, while from the upper phase methanol is recovered by distillation. The methanol is recovered in a percentage of $95 \%$, while biodiesel is then stored under strictly controlled conditions. The flow process diagrams for the examined technologies are given in Figures 2 and 3.

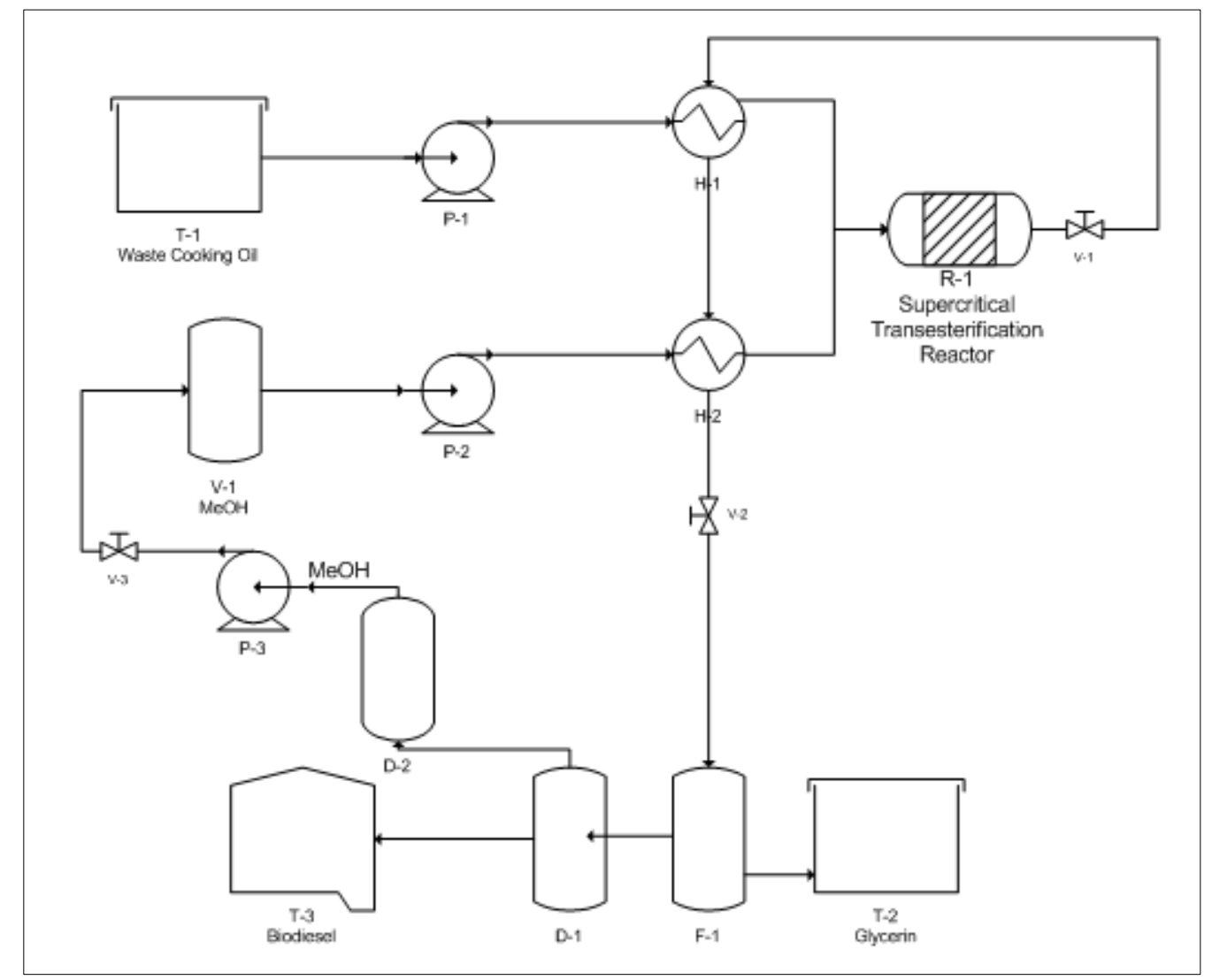

Figure 3. Flow Process Diagram for Supercritical Transesterification (Adapted from Anitescu et al., 2008; Deshpande et al., 2010dmy; Saka et al., 2006)

\section{Financial Analysis and Assessment}

In this section, the results from the performed analysis are presented for both the examined technologies for the price range $0.55-0.85 € / L$ for the product.

Table 2. Project's Investment Capital for the two Technologies (in thousand $€$ )

\begin{tabular}{lcc}
\hline \multicolumn{1}{c}{ Type } & Alkaline Transesterification & Supercritical Transesterification \\
\hline Land & $2,030.0$ & $2,030.0$ \\
\hline Civil Works & 345.00 & 310.00 \\
\hline Equipment and Machinery & $1,056.2$ & $1,077.5$ \\
\hline Pre-investment Expenditures & 80.3 & 78.2 \\
\hline Working Capital $(*)$ & $784.3-859.7$ & $882.0-940.0$ \\
\hline Total $(*)$ & $4,295.8-4,371.2$ & $4,377.7-4,435.7$ \\
\hline
\end{tabular}

$(*)$ According to the biodiesel's final price

The necessary total investment capital is given in Table 2 while Tables 3 and 4 give the evolution of the plant's annual operation cost (for the period 2013-2020) for alkaline transesterification and supercritical 
transesterification respectively, per cost category. It should be mentioned that, obviously, the production cost depends on the final price of biodiesel.

Table 3. Annual Evolution of Operation Cost (in thousand $€$ ) for Alkaline Transesterification (Biodiesel's Price $0.55 € / L$ )

\begin{tabular}{ccccccccc}
\hline Year & $\begin{array}{c}\text { Raw } \\
\text { Materials }\end{array}$ & Personnel & Maintenance & Overhead & $\begin{array}{c}\text { Cost of } \\
\text { Marketing }\end{array}$ & $\begin{array}{c}\text { Financing } \\
\text { Cost }\end{array}$ & Depreciation & Total \\
\hline 2013 & $1,136.1$ & 413.1 & 5.0 & 40.0 & 533.6 & - & 148.2 & $2,276.0$ \\
\hline 2014 & $1,211.6$ & 421.4 & 5.1 & 40.8 & 544.2 & - & 148.2 & $2,371.4$ \\
\hline 2015 & $1,293.2$ & 429.8 & 5.2 & 41.6 & 555.2 & 250.0 & 148.2 & $2,723.2$ \\
\hline 2016 & $1,380.3$ & 438.4 & 5.3 & 42.5 & 566.3 & 217.6 & 148.2 & $2,798.5$ \\
\hline 2017 & $1,473.6$ & 447.2 & 5.4 & 43.3 & 577.6 & 182.0 & 148.2 & $2,877.2$ \\
\hline 2018 & $1,573.4$ & 456.1 & 5.5 & 44.2 & 589.1 & 142.8 & 148.2 & $2,959.3$ \\
\hline 2019 & $1,680.5$ & 465.3 & 5.6 & 45.1 & 600.9 & 99.6 & 148.2 & $3,045.1$ \\
\hline 2020 & $1,795.1$ & 474.6 & 5.7 & 45.9 & 612.9 & 52.2 & 148.2 & $3,134.7$ \\
\hline
\end{tabular}

In the figures that follow, the main results of the financial analysis and assessment are given graphically. Specifically, Figure 4 presents the payback period of the project for the two examined technologies, for the various product's prices. As it can be seen, alkaline transesterification has lower payback period than supercritical transesterification, for all prices considered. Similarly, Figure 5 concerns the Net Present Value (NPV) of the project. From this figure, it is evident that alkaline transesterification is acceptable for the whole range of price while supercritical transesterification is acceptable for prices ranging from 0.75 to $0.85 € / L$. In Figure 6 the Internal Rate of Return (IRR) of the project is presented for both transesterification technologies. For supercritical transesterification, for prices 0.55 to $0.70 € / L$, the IRR can not be calculated as NPV was negative for the respective prices. In the same figure, the reference (interest) rate of the project is presented as well (12\%).

Table 4. Annual Evolution of Operation Cost (in thousand $€$ ) for Supercritical Transesterification (Biodiesel's Price $0.55 € / L$ )

\begin{tabular}{ccccccccc}
\hline Year & $\begin{array}{c}\text { Raw } \\
\text { Materials }\end{array}$ & Personnel & Maintenance & Overhead & $\begin{array}{c}\text { Cost of } \\
\text { Marketing }\end{array}$ & $\begin{array}{c}\text { Financing } \\
\text { Cost }\end{array}$ & Depreciation & Total \\
\hline 2013 & $1,978.2$ & 385.8 & 5.0 & 40.0 & 533.6 & - & 146.6 & $3,089.2$ \\
2014 & $2,070.5$ & 393.6 & 5.1 & 40.8 & 544.3 & - & 146.6 & $3,200.8$ \\
2015 & $2,169.2$ & 401.4 & 5.2 & 41.6 & 555.2 & 250.0 & 146.6 & $3,569.3$ \\
2016 & $2,273.9$ & 409.5 & 5.3 & 42.5 & 566.3 & 217.6 & 146.6 & $3,661.5$ \\
2017 & $2,385.0$ & 417.7 & 5.4 & 43.3 & 577.6 & 182.0 & 146.6 & $3,757.5$ \\
2018 & $2,503.1$ & 426.0 & 5.5 & 44.2 & 589.1 & 142.8 & 146.6 & $3,857.3$ \\
2019 & $2,628.8$ & 434.5 & 5.6 & 45.1 & 600.9 & 99.6 & 146.6 & $3,961.1$ \\
2020 & $2,762.4$ & 443.2 & 5.7 & 45.9 & 612.9 & 52.2 & 146.6 & $4,069.0$ \\
\hline
\end{tabular}

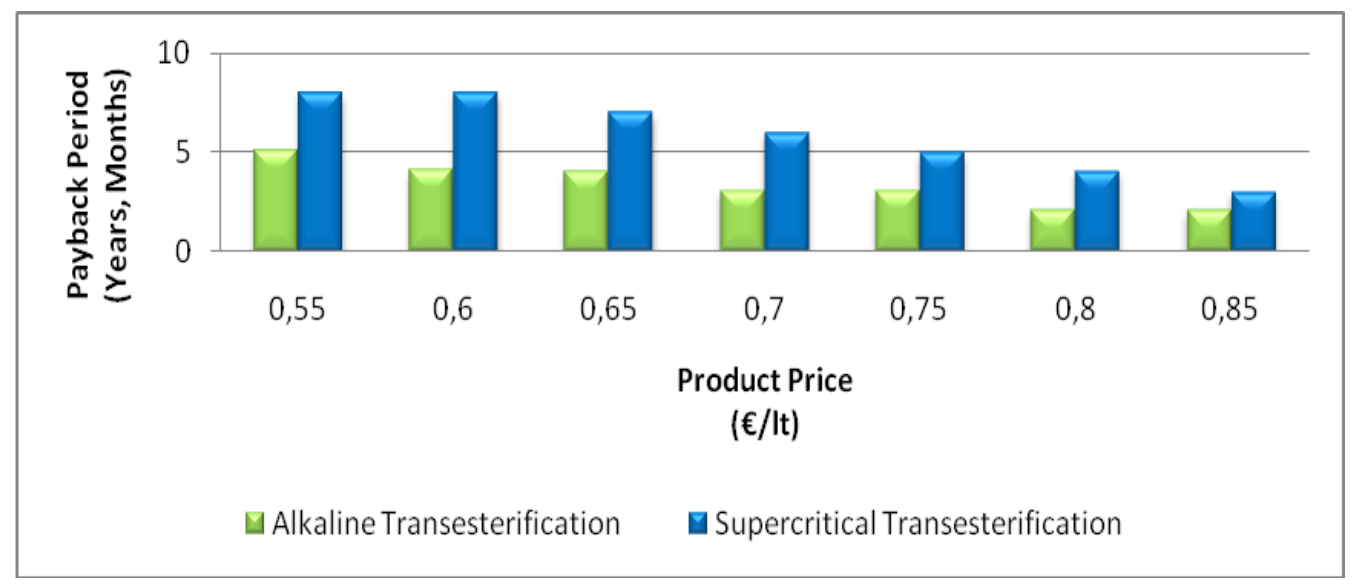

Figure 4. Payback Period versus Product Price for the examined Technologies 


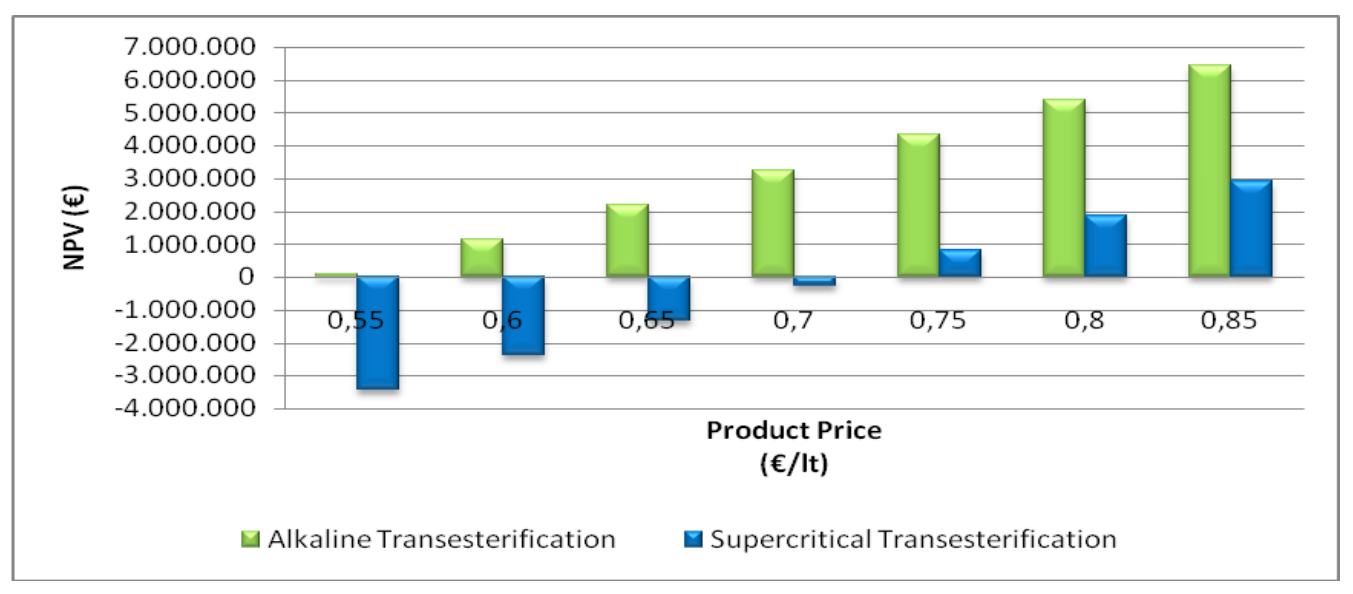

Figure 5. NPV versus Product Price for the examined Technologies

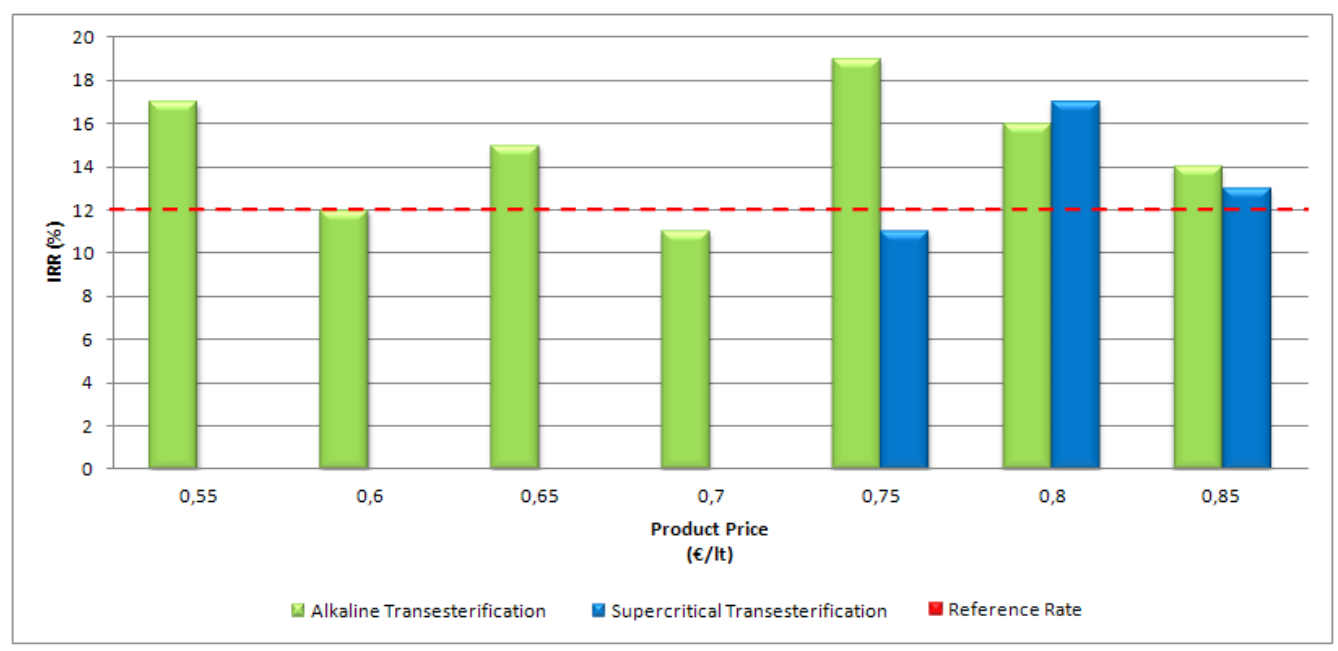

Figure 6. IRR versus Product Price for the examined Technologies

As it can be observed from Figure 6, the project's IRR in the case of the alkaline transesterification is acceptable for biodiesel's prices of $0.75,0.55,0.80,0.65$ and $0.85 € / L$. On the other hand, in the case that the supercritical transesterification process has been selected, the project's IRR is acceptable only for the biodiesel's prices of 0.80 and $0.85 € / L$. However, it is remarkable that the two best cases are this of alkaline transesterification for product's price of $0.75 € / L$ (the IRR is $19 \%$ ) and this of supercritical transesterification for product's price of $0.80 € / L$ (the IRR is $17 \%)$.

\section{Conclusions}

The performed analysis showed the impact of the product's price on the process technology, through the financial attractiveness of the project. Summing up, the examination of the parameters highlighted that the project is acceptable for all prices' range, when the production process is the alkaline transesterification. Conversely, the acceptance of supercritical transesterification depends on the product price, since the examined investment plan could be satisfactory only for biodiesel prices of 0.75 $0.85 € /$ L.

\section{References}

Anitescu G., Deshpande A. and Tavlarides L. (2008), Integrated technology for supercritical biodiesel production and power cogeneration, Energy \& Fuels, 22(2), 1391-1399. 
Apostolakou A., Kookos, I., Marazioti C. and Angelopoulos K. (2009), Techno-economic analysis of a biodiesel production process from vegetable oils, Fuel Processing Technology, 90(7-8), 1023-1031.

Canakci M. (2007), The potential of restaurant waste lipids as biodiesel feedstocks, Bioresource Technology, 98(1), 183-190.

Castellanelli C. and Mello C. (2007), Analyzes of the used fried oil under environmental perspective and its possibilities for production of biodiesel, Department of Production Engineering, Federal University of Santa Maria, Brazil.

Chherti A., Chris Watts K. and Rafiqul Islam M. (2008), Waste cooking oil as an alternate feedstock for biodiesel production, Energies, 1, 3-18.

Demirbas A. (2009), Biodiesel from waste cooking oil via base - catalytic and supercritical methanol transesterification, Energy Conversion and Management, 50, 923-927.

Deshpande A., Anitescu G., Rice P. and Tavlarides L. (2010), Supercritical biodiesel production and power cogeneration: technical and economic feasibilities, Bioresource Technology, 101, 1834-1843.

Dmytryshyn S., Dalai A., Chaudhari S., Mishra H. and Reaney M. (2004), Synthesis and characterization of vegetable oil derived esters: evaluation for their diesel additive properties, Bioresource Technology, 92, 55-64.

European Parliament (2003), Directive 2003/30/EC on the Promotion of the Use of Biofuels or Other Renewable Fuels for Transport, Official Journal of the European Union, L 123/42, Luxembourg.

Fan X., Wang X. and Chen F. (2010), Two novel approaches used to produce biodiesel from low - cost feedstocks, The Open Fuels \& Energy Science Journal, 3, 23-27.

Fukuda H., Kondo A. and Noda H. (2001), Biodiesel fuel production by transesterification of oils, Journal of Bioscience and Bioengineering, 92, 405-416.

Georgakellos D.A. (2002), LCA as a tool for environmental management: A life cycle inventory case study from the Greek market, Global Nest: the Int. J., 4, 93-106.

Groschen R. (2002), Overview of the Feasibility of Biodiesel from Waste/Recycled Greases and Animal Fats, Minnesota Department of Agriculture, Minnesota.

Gui M., Lee K. and Bhatia S. (2008), Feasibility of edible oil vs. non-edible oil vs. waste edible oil as biodiesel feedstock, Energy, 33, 1646-1653.

Hellenic Republic (2005), Law No 3423, Introduction onto the Greek Market of Biofuels and other Renewable Fuels, Government Gazette of the Hellenic Republic, Athens.

Helwani Z., Othman M., Aziz N., Fernando W. and Kim J. (2009), Technologies for production of biodiesel focusing on green catalytic techniques: A review, Fuel Processing Technology, 90, 1502-1514.

Kretzschmar J., Majer S. and Kroeger M. (2012), International overview on waste to biofuel options with a focus on waste potentials in Germany and funding incentives in the EC, Global Nest: the Int. J., 14, 183 -191.

Ngamprasertsith S. and Sawangkeaw R. (2011), Transesterification in supercritical conditions, In: Biodiesel Feedstocks and Processing Technologies, Stoytcheva, M. (ed.), InTech, Rijeka.

Oliveros M., Baiting A., Lumain M. and Cabaraban M. (2007), Ethanol-based biodiesel from waste vegetable oil, AJChE, 7, 83-87.

Papageorgiou P. (2009), Energy Crops and Waste Cooking Oil for Biodiesel Production: Case Study of Greece, M.Sc.Thesis, Department of Land and Water Resources Engineering, Royal Institute of Technology, Stockholm.

Peiro L., Mendez G. and Durany. X. (2008), Exergy analysis of integrated waste management in the recovery and recycling of used cooking oils, Environmental Science and Technology, 42, 4977-4981.

Saka S. and Minami E. (2006), A Novel Non-Catalytic Biodiesel Production Process by Supercritical Methanol as NEDO, The $2^{\text {nd }}$ Joint Int. Conf. on "Sustainable Energy and Environment (SEE 2006)", 21-23 November 2006, Bangkok, Thailand.

San Miguel G., Servert J. and Canoira L. (2010), Analysis of the evolution in biomass to energy strategies and regulations in Spain, Global Nest: the Int. J., 12, 374-383.

Stephenson A., Dennis J. and Scott S. (2008), Improving the sustainability of the production of biodiesel from oilseed rape in the UK, Process Safety and Environment Protection, 86, 427-440. 
Tsai W., Lin C. and Yeh C. (2005), An analysis of biodiesel fuel from waste edible oil in Taiwan, Renewable and Sustainable Energy Reviews, 11, 838-857.

Van Kasteren J. and Nisworo A. (2007), A process model to estimate the cost of industrial scale biodiesel production from waste cooking oil by supercritical transesterification, Resources, Conservation and Recycling, 50, 442-458.

Wang Y., Ou S., Liu P. and Zhang Z. (2007), Preparation of biodiesel from waste cooking oil via two-step catalyzed process, Energy Conversion and Management, 48, 184-188.

Zhang Y., Dube M., McLean D. and Kates M. (2003), Biodiesel production from waste cooking oil: 1.Process design and technological assessment, Bioresource Technology, 89, 1-16. 